\title{
Applications of Data Envelopment Analysis in Development and Assessment of Sustainability Across Economic, Environmental and Social Dimensions
}

\author{
Hamid Hosseini \\ Department of Mathematics \\ Kerman Branch, Islamic Azad \\ University \\ Kerman, Iran
}

\author{
Abbas Ali Noura \\ Department of Mathematics \\ University of Sistan \& Baluchestan \\ Iran
}

\author{
Sara Fanati Rashidi* \\ Department of Mathematics \\ Shiraz Branch, Islamic Azad \\ University \\ Shiraz, Iran
}

\begin{abstract}
Recently, senior managers are paying much more attention to the environmental aspects of decision-making units. Technically, global economy is inextricably connected to the environment, as it is heavily dependent on extraction and exploitation of natural resources. In this article, we try to propose a number of models for efficiency evaluation that combine the growing concepts in environmental areas along with social and economic subjects. Generally speaking, if economic growth is to be continuous and effective in the long term, it must be based on a combination of economic, environmental and social components. The existing literature on data envelopment analysis (DEA) is often based on economic efficiency. However, due to the environmental pollution at a global level, there have been recent studies in relation to sustainability efficiency with focus on environmental and social aspects; although, these studies were limited and left much room for further research. The present study evaluates the efficiency of decision-making units using social, economic and environmental indicators, and tries to minimize the flaws of DEA in the proposed models by making relative comparisons to previous models.
\end{abstract}

Keywords-Data envelopment analysis; desirable and undesirable outputs; strong and weak disposability; sustainability efficiency

\section{INTRODUCTION}

Data envelopment analysis (DEA) is a linear programmingbased method initially proposed by [1]. This method [1] presented a linear programming model (CCR) for efficiency evaluation of decision-making units (DMUs) with multiple inputs and outputs.

Technically, aside from measuring economic efficiency and ranking the units, DEA provides the managers and planners in a given organization with methods for improvement of strategies and all-round growth and development of the organization under study.

Nowadays, a widespread viewpoint is formed suggesting that without consideration to the waste and pollution resulting from industrial activities and production and consumption processes, which would endanger both the environment and the humans, we will not achieve sustainable economic growth.

Therefore, economic, environmental and social policies need to be designed in a way that would effectively improve the efficiency of decision-making units.

So far, a significant amount of research has been dedicated to the applications of DEA; these efforts, however, have been mainly focused on evaluation of DMUs in areas of science and engineering irrelevant to the environment [2] and [3].

In recent years, a number of studies have combined DEA with the life cycle of DMUs in order to evaluate the environmental efficiency of various systems [4]-[8]. Nonetheless, these studies only cover the environmental and economic aspects of sustainability and ignore the social dimension altogether. Some other researchers have used DEA to assess all three of the environmental, social and economic indicators, but they still faced certain challenges combining these three indicators [9]-[12].

Despite its advantages, data envelopment analysis has two major limitations that play a fundamental role during evaluation of sustainability efficiency:

DEA tells us if a unit is efficient or inefficient, but does not discriminate between efficient units (i.e., it does not rank the efficient units). Now, since all efficient units are assigned an efficiency score of one, it would be difficult to choose an alternative in absence of a ranking scheme [13].

When we are faced with large input and output sets based on the number of units, a flaw occurs in the efficiency evaluation and a large number of units are deemed efficient [14].

In this article, we try to eliminate these two flaws through our proposed models. The rest of the article is structured as follows:

In Section 3, we discuss the axioms holding for undesirable outputs (wastes). In Section 4, we engage in efficiency evaluation based on economic, environmental and social

*Corresponding Author 
indicators. In Section 5, we present and solve a numerical example using our suggested models, and make a comparison of results in the end. Our research results will be described in the sixth section.

Technically, the pollution and waste harming the environment are called undesirable outputs.

Undesirable outputs are outputs produced along with the main outputs [15]; due to the nature of undesirable outputs, it is often difficult to determine their prices in the market, something that is usually done by experienced experts using shadow prices.

For instance, paper is produced using the four inputs of pulp, capital, workforce and energy; however, alongside the produced paper, outputs such as biochemical oxygen, suspended solids, sulfur oxides and particles are produced as well, which are impossible to put a market price on [15]. Note that by undesirable output prices, we refer to the costs imposed on us for production of such outputs. Some other examples of such costs would be environmental contamination, disease prevalence and the expenses related to waste management.

\section{AXIOMS HOLDING FOR UNDESIRABLE OUTPUTS}

\section{A. Null-Joint}

Undesirable outputs are null-joint when

?ㅇ? $\left.Y^{D} \cdot Y^{U}\right) \in P P S \quad \cdot Y^{U}=0 \rightarrow Y^{D}=0$

This shows that when the desirable output has a positive value, the undesirable outputs will definitely have positive values as well.

For instance, it would be impossible to produce paper without production of biochemical oxygen, sulfur and so on.

\section{B. Weak Disposability}

In most processes, undesirable outputs are produced alongside desirable outputs.

This axiom states that along with the reduction of desirable outputs, undesirable outputs will decrease as well [15]. In other words, a relative reduction in desirable outputs would require the reduction of undesirable outputs to the same proportion.

Therefore, considering the weak disposability axiom and the standard production set, our new production possibility set (PPS), denoted by $P^{W}(X)$, will be as follows:

$\Pi \Pi \Sigma=P^{W}(X)=\left\{\left(Y^{D K} \cdot Y^{U K}\right): Y^{D K} \leq Y^{D} \lambda \cdot Y^{U K}=\right.$ $\left.Y^{U} \lambda . X \lambda \leq X . \lambda \in R_{+}^{n}\right\}$

Model (1) presents the linear programming form of the PPS. Note that $\mathrm{j}=1,2, \cdots, \mathrm{n}$ represents the number of decisionmaking units that use the input vector $X \in R^{m}$ to produce the desirable output vector $Y \in R^{S}$ and the undesirable output vector $U \in R^{+}$.

$$
\begin{aligned}
& \operatorname{Max} \quad \varphi_{0} \\
& \text { s.t } \\
& \sum_{j=1}^{n} \lambda_{j} x_{j} \leq x_{0} \quad j=1,2, \ldots, n
\end{aligned}
$$

$$
\begin{array}{lr}
\sum_{j=1}^{n} \lambda_{j} y_{j} \geq \varphi_{0} y_{o} & j=1,2, \ldots, n \\
\sum_{j=1}^{n} \lambda_{j} u_{j}=u_{o} & j=1,2, \ldots, n \\
\lambda_{j} \geq 0 & j=1,2, \ldots, n
\end{array}
$$

\section{Strong Disposability}

Similar to the previous topic, this axiom puts certain constraints on the model and states that it is possible to increase the desirable outputs, while preventing undesirable outputs from increasing to the same degree; in some cases, we could even bring the production of undesirable outputs close to zero.

From a profitability perspective, this axiom only cares about increasing desirable outputs and doesn't take a serious look at the production rate of undesirable outputs.

According to the strong disposability axiom and the standard conditions of production possibility set,

$\operatorname{PPS}=\left\{(x . y) \mid x \geq \sum_{j=1}^{n} \lambda_{j} x_{j} \cdot y \leq \sum_{j=1}^{n} \lambda_{j} y_{j} \cdot \lambda_{j} \geq 0 . j=\right.$
$1 . \ldots . n\}$

$P^{S}(X)$ denotes the new production possibility set as presented in the following:

$\operatorname{PPS}=P^{S}(X)=\left\{\left(Y^{D K} . Y^{U K}\right): Y^{D K} \leq Y^{D} \lambda \cdot Y^{U K} \leq Y^{U} \lambda . X \lambda \leq\right.$ x. $\left.\lambda \in R_{+}^{n}\right\}$

Model (2) provides the nonlinear programming problem for this PPS. In this model, we have n DMUs that use the input vector $X \in R^{m}$ to produce the desirable output vector $Y \in R^{S}$ and the undesirable output vector $U \in R^{+}$.

$\operatorname{Max} \varphi_{o}$

$$
\text { s.t }
$$

$\sum_{j=1}^{n} \lambda_{j} x_{j} \leq x_{o} \quad \mathrm{j}=1,2, \ldots, \mathrm{n}$

$\sum_{j=1}^{n} \lambda_{j} y_{j} \geq \varphi_{o} y_{o} \quad \mathrm{j}=1,2, \ldots, \mathrm{n}$

$\sum_{j=1}^{n} \lambda_{j} U_{j} \geq \frac{1}{\varphi_{o}} u_{o} \quad \mathrm{j}=1,2, \ldots, \mathrm{n}$

$\lambda_{j} \geq 0 \quad \mathrm{j}=1,2, \ldots, \mathrm{n}$

\section{EFFICIENCY CALCULATION BASED ON ECONOMIC, ENVIRONMENTAL AND SOCIAL INDICATORS}

The existing literature on data envelopment analysis is mostly based on economic efficiency. Now, since global economy and efficiency evaluation are both influenced by ecological, social and economic components, environmental pollution has influenced the sustainability of efficiency measurement [4].

Since our objective in this research is to measure efficiency in several different dimensions and then combine them together, we can use the following linear programming problem to obtain the sustainability efficiency.

Considering the presence of both desirable and undesirable outputs in real-world situations [15], we propose the following model for assessment of efficiency through economic, 
environmental and social indicators, which are denoted by $\mathrm{d}=$ $1,2,3$, respectively.

Model (3) is used for calculation of efficiency in the mentioned dimensions. In this regard, consider $\mathrm{n}$ decisionmaking units that use the input vector $X \in R^{m}$ to produce the desirable output vector $Y \in R^{S}$ and the undesirable output vector $U \in R^{+}$:

$\operatorname{Min} \theta_{o}^{d}$

s.t

$$
\begin{array}{ll}
\sum_{j=1}^{n} \lambda_{j} x_{j} \leq \theta_{o}^{d} x_{o} & \mathrm{j}=1,2, \ldots, \mathrm{n} \\
\sum_{j=1}^{n} \lambda_{j} y_{j} \geq y_{o} & \mathrm{j}=1,2, \ldots, \mathrm{n} \\
\sum_{j=1}^{n} \lambda_{j} u_{j}=u_{o} & \mathrm{j}=1,2, \ldots, \mathrm{n} \\
\lambda_{j} \geq 0 & \mathrm{j}=1,2, \ldots, \mathrm{n}
\end{array}
$$

$\theta_{o}^{d}$ measures the efficiency of $D M U_{O}$ in dimension d. Note that units with $\theta_{o}^{d}=1$ are efficient and the ones with $\theta_{o}^{d}<1$ are considered inefficient.

The difference between model (3) and models (1) and (2) is that in model (3), we evaluate the DMUs based on their inputs. This is due to the fact that in many situations, like the example used in this study, certain indicators such as economic and social indicators don't have any undesirable outputs, in which case the constraints related to undesirable outputs are removed. Furthermore, the environmental indicator doesn't have any desirable outputs and thus, we can remove the respective constraints; in this case, we can fixate the undesirable outputs and evaluate our DMUs based on their input levels.

In today's world, where most countries, especially industrial countries, put a strong emphasis on the environment and pollution prevention, environmental efficiency is an emerging subject of interest.

Technically speaking, any decision-making unit can affect the whole society in one way or another. For instance, imagine a factory that causes a great amount of environmental pollution despite being economically efficient; undoubtedly, although economic efficiency is an important factor, environmental efficiency is as important to say the least. Another example would be a factory producing socially undesirable products such as tobacco or alcoholic drinks.

In this study, in addition to economic efficiency, we try to consider the social and environmental aspects as well and consider each of them as an indicator or dimension of efficiency.

Technically, the $\theta_{o_{j}}^{d}$ value obtained from model (3) is the efficiency of $D M U_{O}$ in dimension d. [16] proposed the following formula for measurement of mean efficiency:

$\mathrm{j}=1,2, \ldots, n$

$\theta_{o}^{\text {sust }}=\frac{\sum_{d \in D} \theta_{o_{j}}^{d}}{|D|}$

We must note that the CCR model introduced by [1] was used for efficiency calculation, as presented in [16]'s study; due to the previously mentioned reasons, model (3) was used in the prior sections.

\section{NUMERICAL EXAMPLE}

In the current example, 21 Iranian industries are evaluated, where the total capital employed in the industry is considered as the input, value added is the desirable economic output, job creation level is the desirable social output and airborne

\begin{tabular}{|c|c|c|c|c|c|c|c|}
\hline Code & Industry & $\begin{array}{l}\text { Capital } \\
\text { Employed } \\
\text { (input) }\end{array}$ & $\begin{array}{l}\text { Value Added } \\
\text { (desirable } \\
\text { economic } \\
\text { output) }\end{array}$ & $\begin{array}{l}\text { Number of } \\
\text { Workers } \\
\text { (desirable } \\
\text { social output) }\end{array}$ & $\begin{array}{l}\text { so }_{2} \text { (tons) } \\
\text { (undesirable } \\
\text { environmental } \\
\text { output) }\end{array}$ & $\begin{array}{l}\mathrm{co}_{2} \text { (tons) } \\
\text { (undesirable } \\
\text { environmental } \\
\text { output) }\end{array}$ & $\begin{array}{l}\text { SPM (tons) } \\
\text { (undesirable } \\
\text { environmental } \\
\text { output) }\end{array}$ \\
\hline 1 & Food & 10.05 & 8.34 & 15.41 & 37.75 & 11.47 & 16 \\
\hline 2 & Textile & 4.53 & 3.24 & 9.32 & 7.94 & 2.44 & 3.8 \\
\hline 3 & Garment & 0.07 & 0.61 & 0.61 & 0.13 & 0.07 & 0.08 \\
\hline 4 & Leather & 0.16 & 0.32 & 0.85 & 0.53 & 0.13 & 0.26 \\
\hline 5 & Wood & 0.36 & 0.36 & 0.67 & 1.27 & 0.39 & 0.62 \\
\hline 6 & Paper & 0.88 & 0.83 & 1.63 & 0.22 & 1.1 & 1.3 \\
\hline 7 & Publishing & 0.37 & 0.47 & 1.19 & 0.1 & 0.01 & 0.09 \\
\hline 8 & Coke & 4.01 & 11.19 & 1.46 & 13.79 & 13.2 & 10.25 \\
\hline 9 & Material & 33.56 & 14.85 & 7.13 & 7.54 & 11.9 & 8.89 \\
\hline 10 & Rubber Products & 3.15 & 2.7 & 4.71 & 1.93 & 0.93 & 1.15 \\
\hline 11 & Non-metallic Mineral Products & 10.51 & 8.63 & 14.37 & 13.22 & 39.6 & 49.94 \\
\hline 12 & Basic Metals & 16.54 & 17 & 6.44 & 7.79 & 15.1 & 1.07 \\
\hline 13 & Fabricated Metal Products & 1.92 & 3.27 & 6.5 & 0.27 & 1.15 & 1.63 \\
\hline 14 & Machinery & 3.4 & 4.34 & 7.52 & 2.53 & 0.14 & 1.71 \\
\hline 15 & Office Machinery & 0.22 & 0.12 & 0.23 & 0.02 & 0.01 & 0.01 \\
\hline 16 & Power Generating Machinery & 1.59 & 2.78 & 4.82 & 1.06 & 0.57 & 0.7 \\
\hline 17 & Broadcasting & 0.35 & 0.51 & 0.81 & 0.01 & 0.05 & 0.05 \\
\hline 18 & Medical Instruments & 0.26 & 0.45 & 1.04 & 0.3 & 0.11 & 0.17 \\
\hline 19 & Vehicles & 5.82 & 17.54 & 11.09 & 2.49 & 1.18 & 1.62 \\
\hline 20 & Transport Vehicles & 1.24 & 1.84 & 2.56 & 0.47 & 0.2 & 0.3 \\
\hline 21 & Furniture & 1.01 & 0.61 & 1.64 & 0.64 & 0.25 & 0.36 \\
\hline
\end{tabular}
contaminant levels represent the undesirable environmental output [17].

TABLE I. INPUTS AND DESIRABLE AND UNDESIRABLE OUTPUTS FOR THE 21 IRANIAN INDUSTRIES UNDER STUDY 
TABLE II. COMPARISON OF MEAN $\Theta_{0}^{\text {SUST }}$ EFFICIENCY AND $\Phi_{0}$ EFFICIENCY

\begin{tabular}{|c|c|c|c|c|c|c|}
\hline$D M U$ & $\begin{array}{l}\text { Economic efficiency } \\
\text { via model (3) }\end{array}$ & $\begin{array}{l}\text { Social efficiency via } \\
\text { model (3) }\end{array}$ & $\begin{array}{l}\text { Environmental efficiency } \\
\text { via model (3) }\end{array}$ & $\begin{array}{l}\text { Mean } \theta_{o}^{\text {sust }} \\
\text { efficiency via } \\
\text { formula (4) }\end{array}$ & $\begin{array}{l}\varphi_{o} \text { efficiency via } \\
\text { model }(1)\end{array}$ & $\begin{array}{l}\varphi_{o} \text { efficiency via } \\
\text { the nonlinear } \\
\text { model (2) }\end{array}$ \\
\hline 1 & 0.10 & 0.18 & 1 & 0.42 & 1.00 & 1 \\
\hline 2 & 0.08 & 0.24 & 0.47 & 0.26 & 1.00 & 1.342 \\
\hline 3 & 1 & 1 & 0.52 & 0.84 & 1.00 & 1 \\
\hline 4 & 0.23 & 0.61 & 0.90 & 0.58 & 1.00 & 2.414 \\
\hline 5 & 0.11 & 0.21 & 0.96 & 0.42 & 1.0525 & 3.749 \\
\hline 6 & 0.11 & 0.21 & 0.33 & 0.21 & 1.0545 & 3.291 \\
\hline 7 & 0.15 & 0.37 & 0.09 & 0.20 & 1.00 & 2.821 \\
\hline 8 & 0.32 & 0.04 & 1 & 0.45 & 1.00 & 1 \\
\hline 9 & 0.05 & 0.02 & 0.10 & 0.05 & 1.00 & 1.074 \\
\hline 10 & 0.10 & 0.17 & 0.17 & 0.14 & 1.3631 & 2.389 \\
\hline 11 & 0.09 & 0.16 & 1 & 0.41 & 1.00 & 1 \\
\hline 12 & 0.12 & 0.04 & 0.25 & 0.13 & 1.00 & 1 \\
\hline 13 & 0.20 & 0.39 & 0.18 & 0.25 & 1.2960 & 1.635 \\
\hline 14 & 0.15 & 0.25 & 0.21 & 0.20 & 1.5400 & 1.515 \\
\hline 15 & 0.06 & 0.12 & 0.02 & 0.06 & 1.00 & 8.137 \\
\hline 16 & 0.20 & 0.35 & 0.19 & 0.24 & 1.2049 & 1.698 \\
\hline 17 & 0.17 & 0.27 & 0.04 & 0.16 & 1.00 & 2.658 \\
\hline 18 & 0.20 & 0.46 & 0.32 & 0.32 & 1.00 & 1 \\
\hline 19 & 0.35 & 0.22 & 0.12 & 0.23 & 1.00 & 1 \\
\hline 20 & 0.17 & 0.24 & 0.11 & 0.17 & 1.4510 & 2.095 \\
\hline 21 & 0.07 & 0.19 & 0.18 & 0.14 & 1.00 & 4.837 \\
\hline
\end{tabular}

Note that by airborne contaminants, we mean the $\mathrm{CO}_{2}$ (carbon dioxide), SPM (suspended particulate matter) and $\mathrm{SO}_{2}$ (sulfur dioxide) resulted by the use of fossil fuels, as first investigated from an environmental aspect in [17] in Iranian production industries. In this article, their combined efficiency is investigated via the mentioned models based on economic, environmental and social indicators. Data are presented in Table I.

After solving model (1) for the 21 DMUs using MATLAB software and solving model (2) via GAMS, we proceed to solve model (3); Table II provides the results, i.e. mean efficiency scores per economic, social and environmental indicators

\section{CONCLUSION}

In this paper, we made an evaluation of two efficiency calculation methods for decision-making units with undesirable outputs. The first approach involved the models presented by [15], and the second approach employed a modified version of [16] method. Results produced by the two methods were compared within the framework of a numerical example.

According to the results, our proposed approach was able to provide a better ranking among efficient decision-making units.

Our suggested method has improved the discriminatory power of standard DEA by categorizing the inputs through economic, environmental and social indicators. The capabilities of the approach and its applications were demonstrated in a real-world case study, and relative comparisons were made to previous methods.

As can be observed in Table II, 14 DMUs were introduced as efficient based on the weak disposability axiom [15] and 7 units were found efficient under assumption of strong disposability. Meanwhile, using the combined method, only one unit was considered efficient in the economic and social dimensions and three units were deemed efficient based on the environmental indicator; the units were also uniquely ranked using (4). As previously mentioned, this demonstrates the high discriminatory power of our proposed models in respect to efficient units.

\section{REFERENCES}

[1] Charnes A, Cooper WW, and Rhodes E (1978). Measuring the efficiency of decision making units. European journal of operational research, 2(6): 429-444.

[2] Liu JS, Lu LY, Lu WM, and Lin BJ (2013). A survey of DEA applications. Omega, 41(5): 893-902.

[3] Liu JS, Lu LY, Lu WM (2015).Research fronts in data envelopment analysis. Omega, 58: 33-45.

[4] Begum H, Siwar C, Er AC, and Alam ASAF(2016). Environmentally friendly practices of oil palm cultivators. International Journal of Advanced and Applied Sciences, 3(2): 15-19.

[5] Salem SMA, Rahman NAA (2016). The effect of bank-specific factors and unstable macroeconomic environment on bank efficiency: evidence from FCC. International Journal of Advanced and Applied Sciences, 3(9): 97-102.

[6] Dutsenwai HS, Ahmad BB, Tanko AI, and Mijinyawa A (2017). Spatiotemporal analysis of vegetation and oil spill intensity in Ogoniland. International Journal of Advanced and Applied Sciences, 4(4): 81-90.

[7] Mohammadi A, Rafiee S, Jafari A, Keyhani A, Dalgaard T, Knudsen MT, Nguyen TL, Borek R, and Hermansen JE (2015). Joint life cycle 
assessment and data envelopment analysis for the benchmarking of environmental impacts in rice paddy production. Journal of Cleaner Production, 106: 521-532.

[8] Vázquez-Rowe Iand Iribarren D (2014). Review of life - cycle approach coupled with data envelopment analysis: Launching the CFP+DEA method for energy policy making. The Scientific World Journal, 2015: Article ID 813921, 10 pages. https://doi.org/10.1155/2015/813921

[9] Chang DS, Kuo LR, and Chen y (2013). Industrial changes in corporate sustainability performance - an empirical overview using data envelopment analysis. Journal of Cleaner production, 56: 147-155.

[10] Khodakarami M, Shabani A, and Farzipoor Saen R (2014). A new look at measuring sustainability of industrial parks: a two-stage data envelopment analysis approach. Clean Technologies and Environmental Policy, 16(8): 1577-1596.

[11] Reig-Martínez E, Gómez-Limón JA, and Picazo-Tadeo AJ (2011) Ranking farms with a composite indicator of sustainability. Agricultural economics, 42(5): 561-575.
[12] Tajbakhsh A, Hassini E (2014). A data envelopment analysis approach to evaluate sustainability in supply chain networks. Journal of Cleaner Production, 105: 74-85.

[13] Cook WD and Seifore LM (2009). Data envelopment analysis (DEA)thirty years on. European journal of operational research, 192(1): 1-17.

[14] Avkiran NK (2002). Productivity analysis in the service sector with data envelopment analysis. In: Avkiran NK (Ed.), 2nd edition, Camira, Qld.

[15] Fare R, Grosskopf S, Lovell CAK, and Pasurka C (1989). Multilateral productivity comparisons when some outputs are undesirable: a nonparametric approach .The Review of Economics and Statistics,71: 90-98.

[16] Galan-Martin A, Guillen-Gosalbez G, and Stamford L (2016). Enhanced data envelopment analysis for sustainability assessment. Computers and Chemical Engineering, 90: 188-200.

[17] Nasrollahi Z, Sadeghi Aarani Z, and Ghafari Goolak M (2012). Modeling undesirable factors (environmental pollutants) in efficiency evaluation using DEA: A case study of IRAN'S manufacturing industries. Nameh-ye Mofid Journal, 90: 87-110. 